\title{
Vehicles for rural transport services in sub-Saharan Africa
}

Ron Dennis MSc MIMechE, CEng

Former Co-ordinator Developing Technologies (deceased), City, University of London, London, UK
Keith Pullen PhD, DIC, FIMechE, CEng

Professor, Chair in Energy Systems, City, University of London, London, UK (corresponding author: k.pullen@city.ac.uk)

There is a critical lack of affordable transport services linking villages to markets, healthcare and other facilities in rural areas of sub-Saharan Africa, which significantly restrains rural development. A key factor is the severe constraint on profitability of services due to the high operating costs of conventional vehicles operating at relatively low speeds on rural roads. This paper argues that there is a need to consider lower-speed alternatives based on motorcycles. It shows that motorcycle-based vehicles such as trailers and three-wheelers can carry loads up to $1 \mathrm{t}$ on rural roads when geared down to an appropriate speed. The operating costs of these vehicles are shown to be around half those of conventional vehicles, greatly increasing the potential for setting up profitable transport services. Further development is needed to show that motorcycle-based vehicles can be used safely and profitably to help rural people improve their livelihoods and facilitate rural development.

\section{Introduction}

Around $60 \%$ of people in sub-Saharan Africa (sSA), including $80 \%$ of the poorest, live in rural villages (Olinto et al., 2013) and grow subsistence crops on small plots of land to support themselves. Their livelihoods depend largely on selling surplus crops at market and this is the main driver of rural development, linked to a growing demand for food that results from increasing urbanisation. However, this is severely constrained by long distances to markets, poor roads and a lack of affordable transport. As people are generally too poor to own vehicles there is a great need for affordable transport services to provide access to markets, healthcare and other essential services. Unfortunately these are generally lacking. Although there are several complex factors that affect the supply and affordability of rural transport services (RTS) it is argued in this paper that a key factor is that conventional vehicles designed to operate at high speeds on paved roads operate inefficiently at low speeds on rural earth roads with high fuel consumption and emissions. This creates high operating costs, which are a substantial barrier to providing profitable but affordable RTS. There is hence a strong case for introducing more appropriate, lower-speed vehicles, which can be operated profitably to provide the much-needed services. This paper reviews this need and proposes a solution based on motorcycle-based vehicles (MBVs). Two possible options, trailers and three-wheelers, are discussed and the successful field trials of a particular example of a motorcycle-based emergency transport service vehicle, a motorcycle ambulancetrailer (MAT), carried out by Developing Technologies in Zambia are described.

\section{Rural transport services in sub-Saharan Africa}

Case studies in four countries by Starkey et al. (2007) found that a general model can be used to describe the pattern of RTS in sSA. This is the 'hub and spoke' concept shown in Figure 1 in which the hubs are the main locations between which RTS operate and the spokes are the roads on which they run.

The RTS that exist are generally found at the upper end of the network on trunk roads, where there is a concentrated and steady demand that allows RTS operators to make a profit. However, even here there may be considerable delays for users as operators wait to get full loads to achieve that profitability.

The big gap in RTS is usually in the links between villages and markets, health facilities and other resource facilities. This is the most critical area for rural communities providing access to markets and health and other services. The lack of RTS in this area is a key constraint on improving rural livelihoods and rural growth.

The role and importance of these 'village-to-local resource centre' RTS are emphasised in a number of other recent key reviews of rural transport in sSA, including Starkey and Njenge (2010), Banjo et al. (2012), Porter (2013), Starkey et al. (2013) and Hine (2014). The authors note that that the main investment, up to $98 \%$, in rural transport has been in infrastucture. There has been a very limited investment in promoting appropriate transport such as bicycles and animal-drawn carts, but almost nothing in motorised RTS. It has been generally assumed that once roads were upgraded the RTS would follow automatically, as transport operators saw the opportunities provided. However, this has not happened and the reviews show that it is very difficult to make a profit with conventional RTS on village-to-market routes for a number of reasons.

- Demand is dispersed, irregular and seasonal.

- Roads tend to be poor and therefore vehicle operating costs are high. 
Transport

Volume 170 Issue TR6
Vehicles for rural transport services in sub-Saharan Africa

Dennis and Pullen

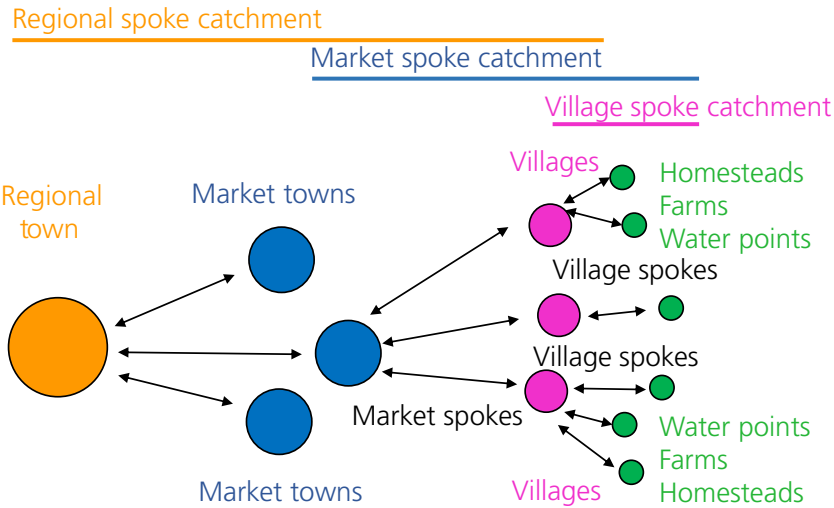

Figure 1. Representation of rural transport services (after Starkey et al., 2007)

\section{- Incomes and therefore affordability are low. \\ - Payloads may be low. \\ - There is limited back-up support for vehicle operations.}

A key factor in this is the high operating costs of conventional vehicles designed for medium to high speeds on bitumen roads when operated on typical rural earth/gravel roads at lower speeds. Typical vehicles used are minibuses and converted pickups, as shown in Figure 2. The majority of these vehicles are imported as reconditioned vehicles and are probably at least 5 years old when they go into service initially on main hub routes, then by the time they filter down to rural routes they will usually be well over 10 years old (Starkey et al., 2013).

Using a specific fuel consumption map, an estimated comparison of the fuel consumption and carbon dioxide $\left(\mathrm{CO}_{2}\right)$ emissions of a typical 21 engine used in these vehicles when operating on bitumen and earth/gravel roads is shown in Figure 3. This shows that, when operating at an average speed of $50 \mathrm{~km} / \mathrm{h}$ on earth/gravel roads, the fuel consumption and carbon dioxide emissions are about double those at an average speed of $80 \mathrm{~km} / \mathrm{h}$ on bitumen roads. As maintenance costs will also be significantly higher on the rougher earth/gravel roads and journey times will be longer, operating costs are likely to be at least double those on bitumen roads. Unfortunately, it is very difficult to obtain any reliable data on this (Starkey et al., 2013) and no specific data are available. Because of the relatively small number of vehicles involved, the impact of the higher carbon dioxide emissions is probably negligible, but clearly it is an undesirable effect. Increased nitrous oxide emissions are also of concern, particularly where roads pass through villages.

\section{Motorcycle-based vehicles}

It seems clear that to increase the availability of RTS the operating costs of RTS vehicles need to be reduced to make services profitable at affordable fares and therefore vehicles more appropriate to the operating conditions need to be considered. This points to vehicles of lower power, with a maximum speed of about half that of conventional vehicles.

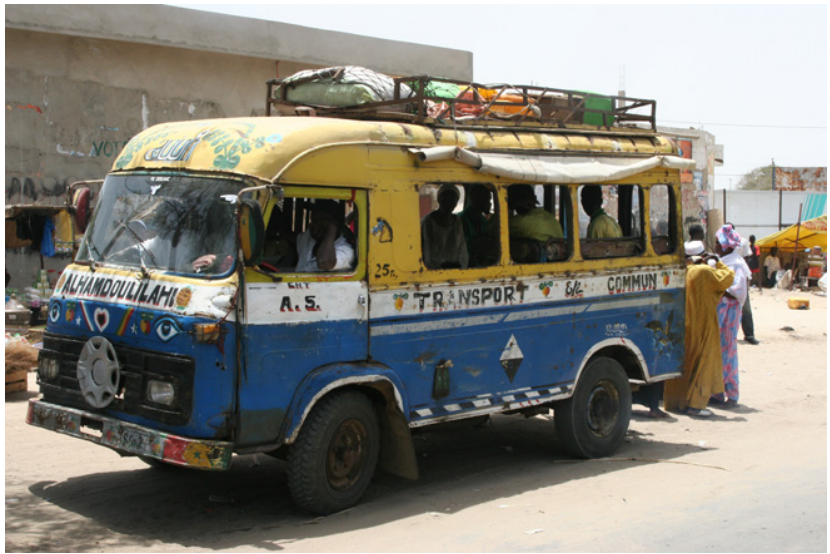

(a)

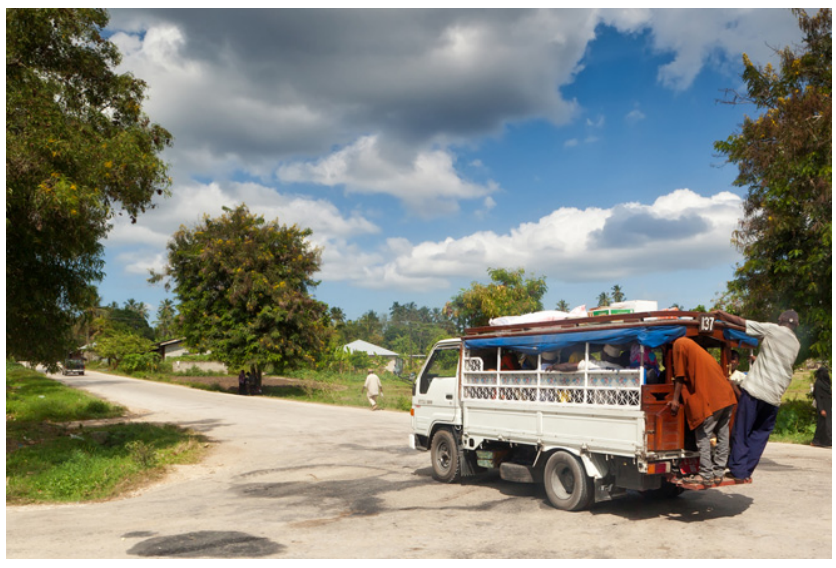

(b)

Figure 2. Typical rural transport vehicles: (a) minibus; (b) adapted pickup truck

Motorcycles are the fastest growing mode of transport in sSA. For example, the motorcycle fleet in Tanzania has increased from 31006 in 2005 to 323192 in 2010, an annual growth rate of $60 \%$ (Hine, 2014). These have already had a considerable impact on improving the mobility of people in several areas of sSA through the introduction of taxi services where one or two persons are carried on the pillion seat behind the rider. It therefore seems logical to consider the adaptation of motorcycles to transport larger numbers of people and goods.

Motorcycle-based vehicles are widely used in some countries in Asia for carrying quite large loads. Figure 4 shows the two possible options, a trailer and a three-wheeler. Motorcycle trailers are common in Cambodia and Vietnam for carrying people and goods, whereas three-wheelers are widely manufactured and used in China. Sperling et al. (2004) report that over a million of these vehicles are produced annually and play a major role in rural transport for carrying goods and people.

The majority comprise a small diesel engine and three-speed gearbox, but motorcycle adaptations are also common 
Vehicles for rural transport services in sub-Saharan Africa

Dennis and Pullen

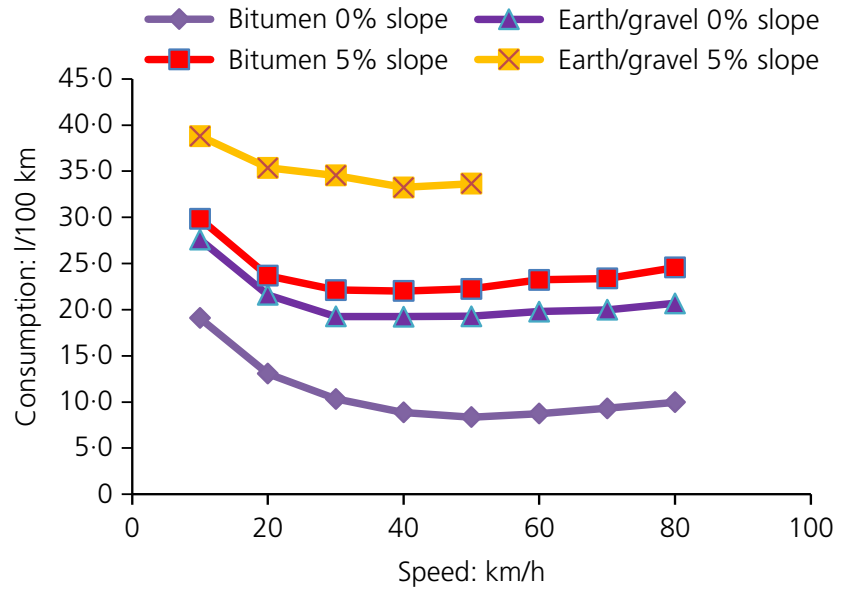

(a)

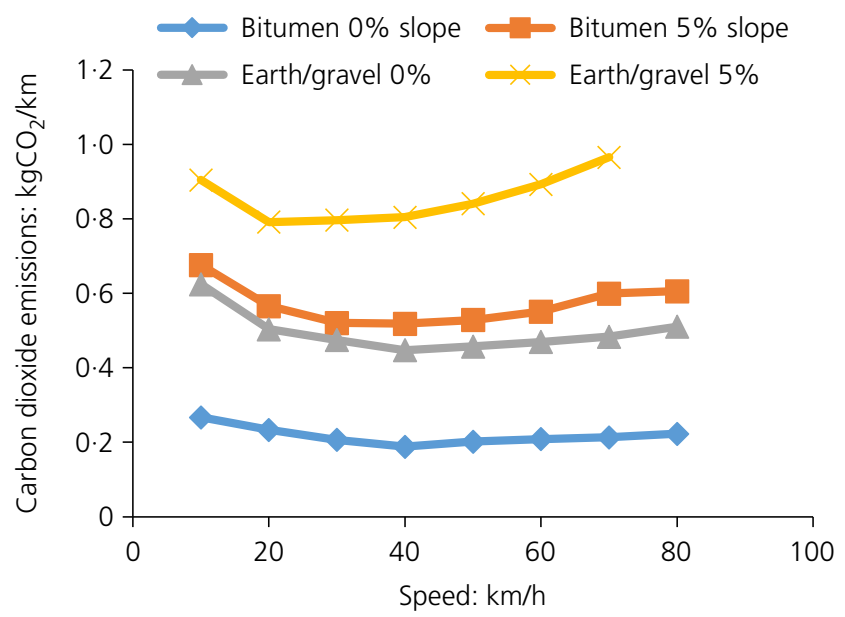

(b)

Figure 3. Comparison of (a) fuel consumption and (b) carbon dioxide emissions on bitumen and earth/gravel roads

(Dalkmann et al., 2008). These types of vehicles are viable in China where there is a vast resource of components and spare parts to support their manufacture and operation. The situation in sSA is completely different and, for sustainability, vehicles need to be based on readily available technologies, for instance adaptations of commonly available motorcycles. Trailers would in fact be the easiest to introduce as they can be readily manufactured in local workshops and used with available motorcycles. However, there is some concern regarding their stability on rural roads when carrying heavy loads, particularly people. Three-wheelers seem intuitively more stable, but there have been concerns about overturning in cornering, even on smooth surfaces (Challener et al., 2000). This problem will be considerably exaggerated on rough surfaces and there must be some concern about their safety when operating on rural roads. No research on this has been found and it seems highly desirable that stability studies are carried out to prove their safety before they are widely introduced for RTS.

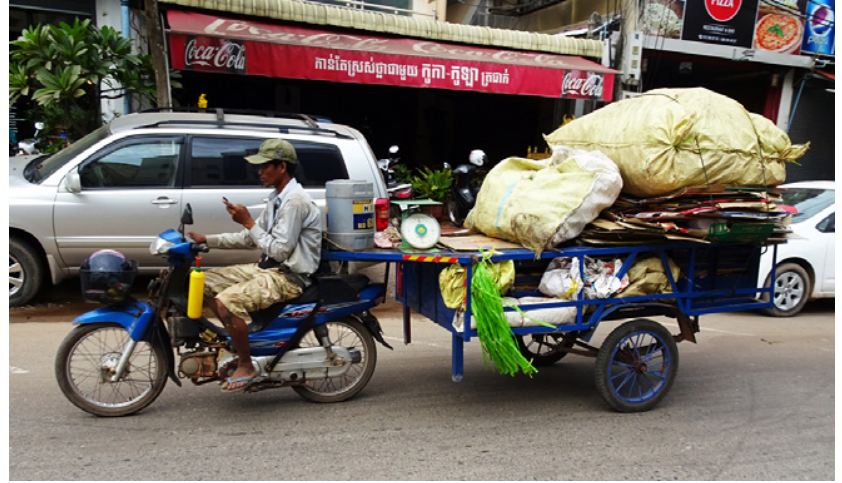

(a)

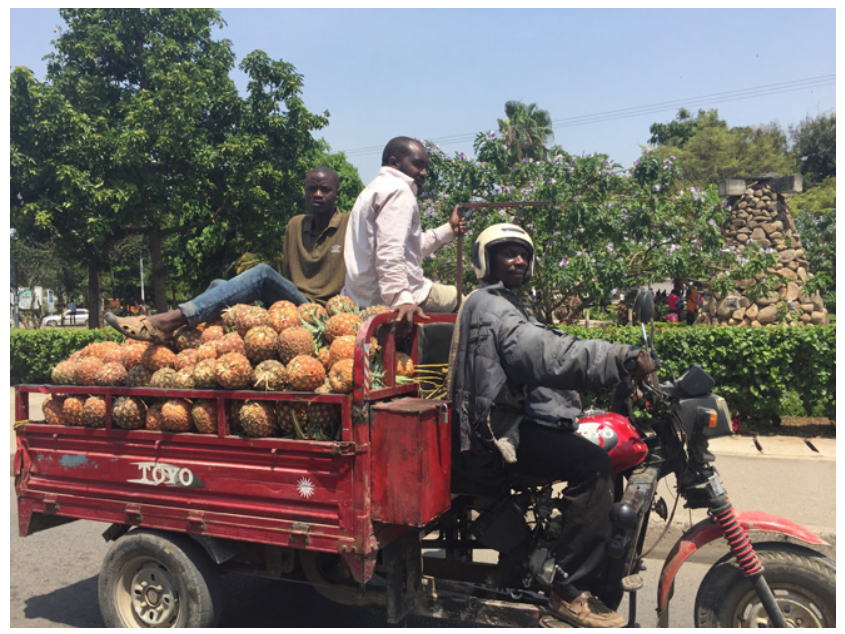

(b)

Figure 4. Motorcycle-based vehicles: (a) motorcycle trailer; (b) motorcycle three-wheeler

Figure 5 shows an illustration of the concept of a three-wheeler based on a motorcycle in which the swing-arm and rear wheel of the motorcycle are removed and the bike is then attached to a load-carrying chassis with a two-wheel rear axle. The drive would be by chain from the gearbox by way of one or more intermediate shafts, which would give the required gear reduction to a differential or overrunning clutches on the rear axle.

Figure 6 shows the predicted performance of such a vehicle on earth/gravel roads with a $250 \mathrm{cc}$ engine, a maximum speed of $40 \mathrm{~km} / \mathrm{h}$ and carrying a payload of $1000 \mathrm{~kg}$ (equivalent to about ten people and their goods). It is seen that with the vehicle geared down to reduce the maximum speed to $40 \mathrm{~km} / \mathrm{h}$ it is comfortably able to transport loads of up to $1000 \mathrm{~kg}$ on slopes up to 1 in 10 on earth/gravel roads. The average journey speed of around $30 \mathrm{~km} / \mathrm{h}$ would be quite adequate for transport services linking villages to market/resource centres where maximum distances will generally be 25 to $30 \mathrm{~km}$. 


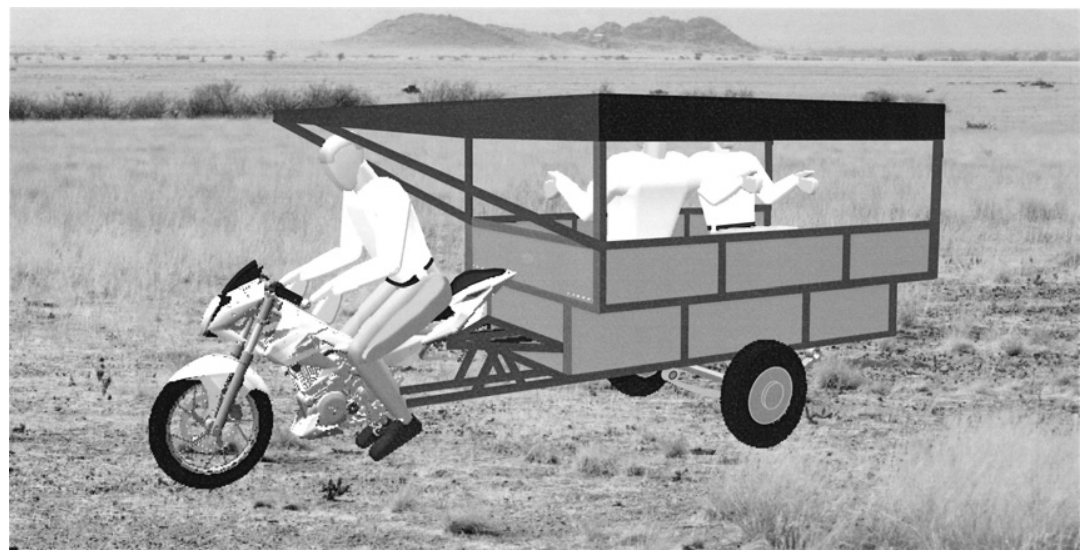

Figure 5. Concept of three-wheeler adaptation of a motorcycle

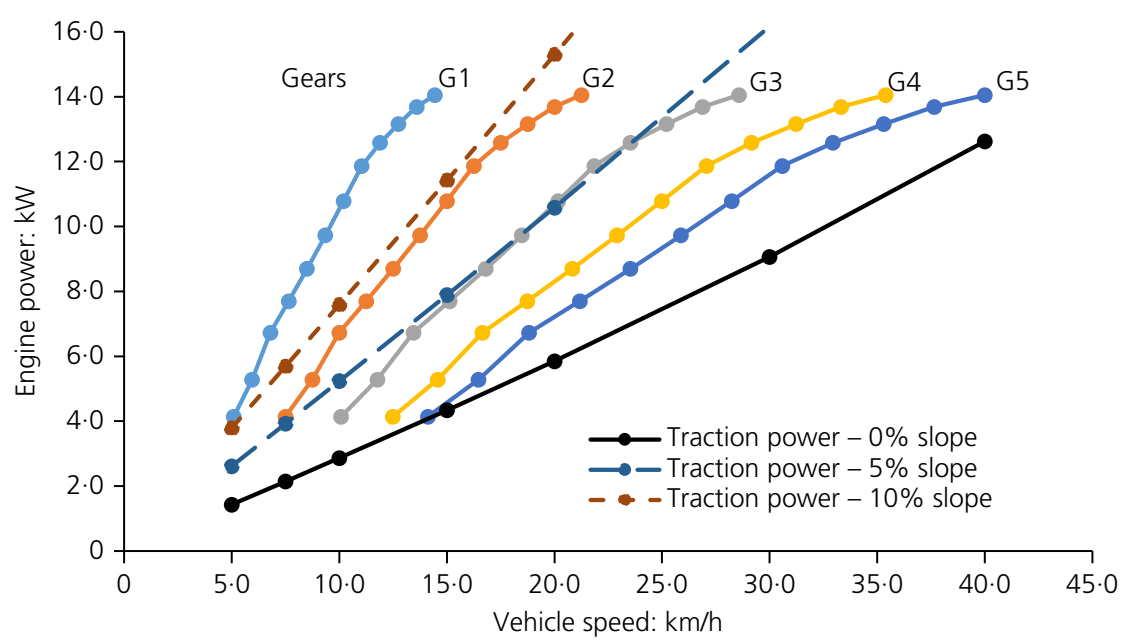

Figure 6. Performance of $250 \mathrm{cc}$ MBV on earth/gravel road with $1000 \mathrm{~kg}$ load

Figure 7 shows that the estimated fuel consumption of the MBV operating at an average speed of $30 \mathrm{~km} / \mathrm{h}$ is around half that of a pickup operating at $50 \mathrm{~km} / \mathrm{h}$ carrying loads of $1000 \mathrm{~kg}$ on earth/gravel roads. Experience from the MAT trials discussed below indicates that maintenance costs for an MBV will be less than half those for a conventional vehicle, so it can be confidently predicted that operating costs of the MBV will be at least $50 \%$ less than those of a conventional RTS vehicle, greatly increasing the possibility of running profitable RTS at affordable fares.

An indicative break-even fare for an MBV transport service is estimated using the following assumptions

- fuel - 12 1/100 km at US\$1·80/1 gives US\$0 $22 / \mathrm{km}$

- repair and maintenance $-10 \%$ of initial cost of $\$ 9000$ and $10000 \mathrm{~km} /$ year gives $\$ 0 \cdot 09 / \mathrm{km}$

- depreciation - initial cost of $\$ 9000$ and life of $80000 \mathrm{~km}$ gives $\$ 0 \cdot 11 / \mathrm{km}$

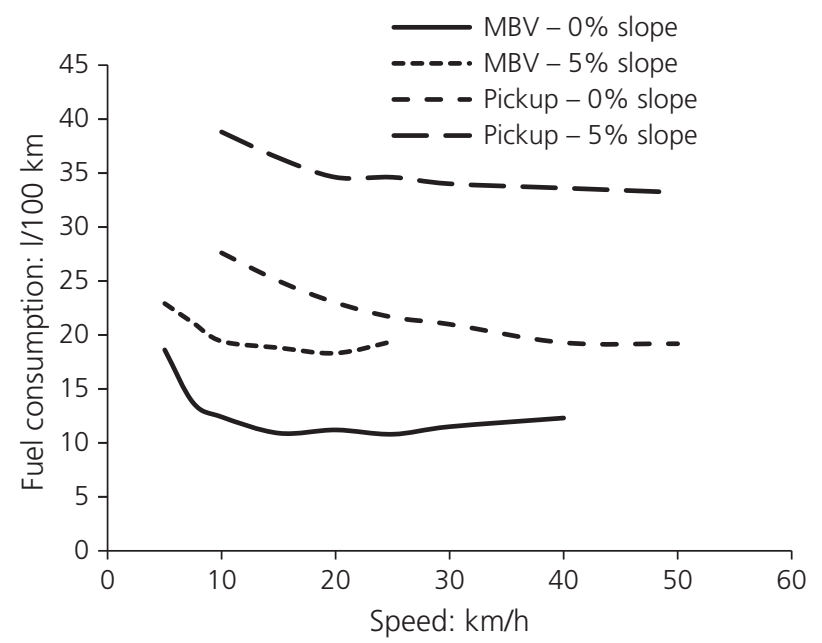

Figure 7. Comparison of fuel consumption of the MBV with pickup 
Allowing for other fixed costs this gives an indicative break-even cost of $\$ 0.45 / \mathrm{km}$, or 4.5 US cents/passenger $\mathrm{km}$. Assuming $75 \%$ of income-earning capacity this increases to 6 US cents/passenger $\mathrm{km}$. Typical minibus fares for passenger with a $30 \mathrm{~kg}$ load are reported as 7 to $14 \mathrm{US}$ cents $/ \mathrm{km}$ (Starkey et al., 2013), but it is pointed out that these probably do not allow for depreciation and are therefore not sustainable in regard to vehicle replacement; also, they involve excessive overloading of vehicles. In addition, most minibus services operate on more well-used routes, with few on rural routes from villages. A more relevant comparison may be with motorcycle taxis, which are commonly used on these routes and typically charge 20 to $25 \mathrm{US}$ cents/passenger km (Starkey et al., 2013). It can therefore be seen that MBV transport services could roughly halve fares.

Vehicle emissions for RTS are of limited concern at present because of the very small numbers involved, but will become of increasing significance as numbers grow and therefore need to be considered in advocating new types of vehicles. Emissions for MBVs are discussed in a report by Meszler Engineering services for the International Council on Clean Transportation (Meszler, 2007). Owing to less sophisticated exhaust controls, emissions of noxious exhaust gases are higher for motorcycles than for fourwheel vehicles but are decreasing because of the swing from two-stroke to four-stroke engines - it is estimated that almost $80 \%$ of such vehicle production is now four-stroke models. In regard to 'greenhouse' gas, carbon dioxide, Meszler quotes a figure of $80 \mathrm{~g} / \mathrm{km}$ for a $250 \mathrm{cc}$ four-stroke motorcycle. This is roughly one-third of a typical passenger vehicle of $257 \mathrm{~g} / \mathrm{km}$ quoted by the US Environmental Protection Agency (US EPA, 2014) and supports the above prediction that the introduction of MBVs would substantially reduce emissions of carbon dioxide. It might also be noted that, because of the age of the conventional RTS vehicles, the fuel consumption and carbon dioxide emissions are likely to be greater than those estimated.

\section{Field trials of a motorcycle ambulance-trailer}

An example of an MBV is the MAT developed and trialled by Developing Technologies based on a concept initially developed by the author and tested in Tanzania. Figure 8 shows an MAT being used in Zambia.

The MAT has the following features.

- There is the capacity to carry a patient on a stretcher and one or two carers. The latter is essential in many countries in sSA where carers are needed to look after patients when admitted to clinic or hospital.

- There is a sprung suspension to improve the ride on earth/gravel roads. The suspension comprises leaf springs from a Toyota Hilux vehicle.

- The vehicle possesses car wheels with cable-operated drum brakes. These are automatically applied when the trailer

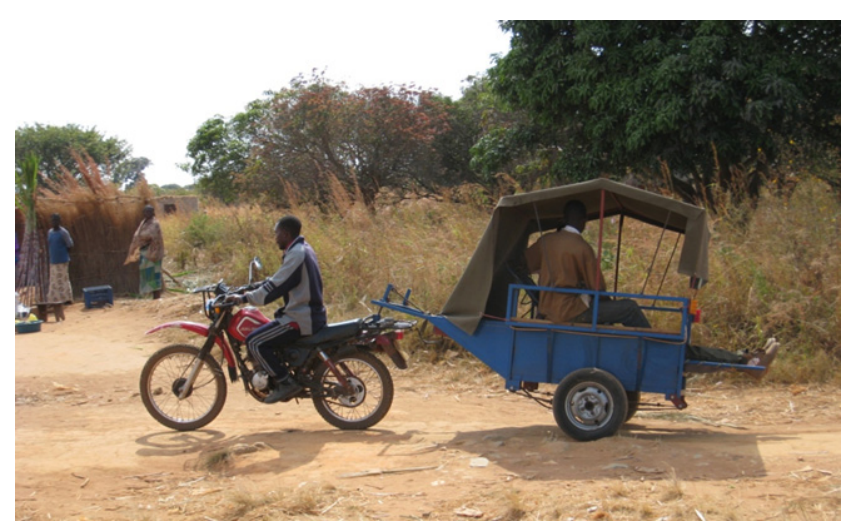

Figure 8. Motorcycle ambulance trailer in use in Zambia

pushes forward on the motorcycle by a pivoting hitch pin arrangement.

- There is a canopy for weather protection.

The MAT has been comfortably towed by a $125 \mathrm{cc}$ motorcycle, although a $200 \mathrm{cc}$ model would be preferred to reduce strain on the bike. It is coupled to the motorcycle by a ball hitch mounted in a socket attached on the motorcycle as closely as possible above the rear axle. It was found from initial instrumented trials with different hitch positions that this location seemed to have the least impact on rider control of the bike. It was hypothesised that, in this position, the forces from the trailer tend to cause roll of the bike, which is easier for the rider to control than transverse twisting moments applied when the hitch is at axle level.

Two MATs have been trialled in Zambia in the Africa Community Access Programme (AFCAP) over a period of 16 months (Dennis and Pullen, 2015), and have continued in operation since the end of the project. The MATs were located at clinics in Lundazi District in Eastern Province and were used to collect emergency patients from surrounding villages. During the project the MATs completed over 400 trips, about $60 \%$ were maternity patients, and over $15000 \mathrm{~km}$, greatly improving access to healthcare for the local communities and saving many lives. The average distance to a clinic in the area is $7 \mathrm{~km}$ and the maximum is about $20 \mathrm{~km}$. Without the MATs, the villagers would be faced with lengthy and laborious trips by walking, bicycle or, in a few cases, by ox-cart. Emergency patients therefore often would not travel to the clinic because of the difficult journey or would arrive too late for effective treatment.

No safety problems were reported for the MATs. The operators reported that it took them 2 to 3 weeks to build up confidence in towing the MAT, but then they felt comfortable to tow it up to $40 \mathrm{~km} / \mathrm{h}$ when empty and 25 to $30 \mathrm{~km} / \mathrm{h}$ when full. Logbook records showed an average trip speed of $25 \mathrm{~km} / \mathrm{h}$. However, they reported that control of the bike was tiring on 


\begin{tabular}{|c|c|c|c|c|c|c|c|}
\hline \multirow[b]{2}{*}{ Ambulance type } & \multirow[b]{2}{*}{$\begin{array}{l}\text { Initial cost: } \\
\text { US \$ }\end{array}$} & \multicolumn{4}{|c|}{ Running costs: $\$ / \mathbf{k m}$} & \multirow[b]{2}{*}{$\begin{array}{l}\text { Depreciation }^{\text {b: }} \\
\$ / \mathbf{k m}\end{array}$} & \multirow[b]{2}{*}{$\begin{array}{l}\text { Total operating } \\
\text { costc }^{c}: \$ / \mathbf{k m}\end{array}$} \\
\hline & & $\begin{array}{l}\text { Fuel used: } \\
\qquad \mathrm{km} / \mathrm{l}\end{array}$ & $\begin{array}{c}\text { Fuel } \\
\text { cost } / \mathrm{km}^{\mathrm{a}}\end{array}$ & $\begin{array}{l}\text { Repair and } \\
\text { maintenance }\end{array}$ & Total & & \\
\hline Landcruiser & 60000 & $6 \cdot 5$ & 0.26 & 0.32 & 0.58 & 0.26 & 0.84 \\
\hline MAT with $125 \mathrm{cc} \mathrm{m} / \mathrm{c}$ & 5500 & 28 & 0.06 & $0 \cdot 12$ & $0 \cdot 18$ & 0.08 & 0.26 \\
\hline
\end{tabular}

${ }^{\mathrm{a}}$ Based on fuel price of $\$ 1 \cdot 7 / 1$

${ }^{\mathrm{b}}$ This is the annual replacement cost based on 4\% inflation and assuming for Landcruiser - $25000 \mathrm{~km} / \mathrm{year}$ and total life $300000 \mathrm{~km}$; MAT - $10000 \mathrm{~km} / \mathrm{year}$ and total life $80000 \mathrm{~km}$

${ }^{c}$ Other costs may include annual road tax and insurance (depending on government requirements), operator costs and protective clothing for riders

the arms and it was necessary to rest after about $1 \mathrm{~h}$. Other problems were reported as follows.

- The MAT tends to bounce when empty but this disappears when loaded.

- The width of the MAT makes rear vision a problem.

- There is some jerkiness from the overrunning braking system.

- There was some difficulty with control on some wet surfaces during the rainy season due to a loss of traction on the slippery surface.

These issues will be addressed in the development of an upgraded version, which is currently being tested. It is considered that this further field experience is needed as a foundation for scaling up the introduction of the MAT.

The operating costs of the MAT compared to a conventional Landcruiser ambulance are shown in Table 1, based on monitoring data obtained in the Zambia project. It is seen that the initial cost of the MAT is about $10 \%$ of the cost of a Landcruiser ambulance and the total operating cost about $30 \%$. This reinforces the estimated comparison for the RTS vehicles that the operating cost of the larger MBV would be around $50 \%$ of conventional vehicles.

\section{Conclusions}

The paper shows that MBVs have great potential to provide effective and profitable transport services at affordable fares in rural areas of sSA. If geared down to an appropriate maximum speed of $40 \mathrm{~km} / \mathrm{h}$, MBVs based on a $250 \mathrm{cc}$ motorcycle can comfortably carry or tow loads up to $1 \mathrm{t}$, equivalent to ten people and their goods, on rural earth/gravel roads, making them highly appropriate for providing RTS linking villages to markets and other facilities. The operating costs are estimated to be around $50 \%$ of conventional RTS vehicles, greatly increasing the potential for setting up economically viable RTS.

It is envisaged that the widespread introduction of RTS using MBVs will have a major impact on increasing the mobility of rural people in sSA, leading to improvements in livelihoods and for rural economies. Service operators will need to develop routes and schedules that provide reliable, convenient and regular services for rural communities to maximise usage, so that services can be run at a profit while keeping fares affordable. It seems likely that these will initially be based on market days, enabling families to carry more goods to market with a much reduced burden of time and effort; however, as incomes grow, there will be increasing usage for other purposes, therefore increasing the viability of the services.

\section{REFERENCES}

Banjo G, Gordon H and Riverson J (2012) Rural Transport, Improving its Contribution to Growth and Poverty Reduction in Sub-Saharan Africa. Sub-Saharan Africa Transport Policy Program (SSATP), Africa Region, The World Bank, Washington, DC, USA.

Challener S, Chan K and Lock G (2000) Stability of 3 and 4 Wheeled Vehicles. Frazer Nash Consultancy, Dorking, UK, Report FNC 5352/19708R Issue 1. See http://www.hse.gov.uk/research/crr_pdf/ 2000/crr00289.pdf (accessed 25/02/2017).

Dalkmann H, Hutfilter S, Vogelpohl K and Schnabel P (2008) Sustainable mobility in rural China. Journal of Environmental Management 87(2008): 249-261.

Dennis R and Pullen K (2015) Improving access to emergency healthcare in sub Saharan Africa. World Transport, Policy and Practice 21(2): $8-20$.

Hine J (2014) Good Policies and Practices on Rural Transport in Africa. Sub-Saharan Africa Transport Policy Program (SSATP), World Bank, Washington, DC, USA, Working Paper No. 100.

Meszler D (2007) Air Emissions Issues Related to Two and Three-wheeled Motor Vehicles: An Initial Assessment of Current Conditions and Options for Control. Prepared by Meszler Engineering Services for The International Council on Clean Transportation, Washington, DC, USA.

Olinto P, Kathleen B, Sobrado C and Uematsu H (2013) The State of the Poor: Where Are the Poor, Where Is Extreme Poverty Harder to End, and What Is the Current Profile of the World's Poor? The World Bank, Washington, DC, USA, Economic Premise Number 125 .

Porter G (2013) Transport Services and their Impact on Poverty and Growth in Rural sub-Saharan Africa. African Community Access Programme, UKaid, London, UK. See https://assets.publishing. service.gov.uk/media/57a08a43ed915d3cfd00068c/AFCAP-GEN060-J-Transport-Services-Poverty-and-Growth.pdf (accessed 25/02/2017). 
Transport

Volume 170 Issue TR6
Vehicles for rural transport services in

sub-Saharan Africa

Dennis and Pullen
Sperling D, Lin Z and Hamilton P (2004) Chinese Rural Vehicles: An Exploratory Analysis of Technology, Economics, Industrial Organization, Energy Use, Emissions, and Policy. Institute of Transportation Studies, University of California, Davis, CA, USA, Research Report UCD-ITS-RR-04-01.

Starkey P and Njenge P (2010) Improving sustainable rural transport services: constraints, opportunities and research needs. Proceedings of the 1st AFCAP Practitioners' Conference, Addis Ababa, Ethiopia. See http://www.ruraltransport.info/RTSi/docs/ Starkey-Njenga-2010-RuralTransportServicesAFCAPETworkshop.pdf (accessed 25/02/2017).

Starkey P, Awadh A, Kemptsop G, Musonda H and Sirpé G (2007) Rural Transport Services in Africa, Lessons from Rapid
Appraisal Surveys in Burkina Faso, Cameroon, Tanzania and Zambia. Sub-Saharan Africa Transport Policy Program (SSATP), Africa Region, The World Bank, Washington, DC, USA.

Starkey P, Njenga P, Kemptsop G et al. (2013) Rural Transport Services Indicators. International Forum for Rural Transport and Development (IFRTD), for African Community Access Programme, London, UK, Final Report.

US EPA (US Environmental Protection Agency) (2014) Greenhouse Gas Emissions from a Typical Passenger Vehicle. US Environmental Protection Agency, Washington, DC, USA. See http://www3. epa.gov/otaq/climate/documents/420f14040a.pdf (accessed 25/02/2017).

\section{How can you contribute?}

To discuss this paper, please email up to 500 words to the editor at journals@ice.org.uk. Your contribution will be forwarded to the author(s) for a reply and, if considered appropriate by the editorial board, it will be published as discussion in a future issue of the journal.

Proceedings journals rely entirely on contributions from the civil engineering profession (and allied disciplines). Information about how to submit your paper online is available at www.icevirtuallibrary.com/page/authors, where you will also find detailed author guidelines. 